\title{
Health Related Quality of Life in Interstitial Lung Disease: Can We Use the Same Concepts Around the World?
}

\author{
Kerri I. Aronson ${ }^{1 *}$ and Atsushi Suzuki ${ }^{2}$ \\ 1 Division of Pulmonary and Critical Care Medicine, Weill Cornell Medicine, New York, NY, United States, ${ }^{2}$ Department of \\ Respiratory Medicine, Nagoya University Graduate School of Medicine, Nagoya, Japan
}

Health-Related Quality of Life (HRQOL) is increasingly viewed as an important patientcentered outcome by leading health organizations, clinicians, and patients alike. This is especially true in the interstitial lung disease community where patients often struggle with progressive and debilitating disease with few therapeutic options. In order to test the effectiveness of new pharmacologic therapies and non-pharmacologic interventions globally in ILD, this will require expansion of clinical research studies to a multinational level and HRQOL will be an important endpoint to many. In order to successfully expand trials across multiple nations and compare the results of studies between different

OPEN ACCESS

Edited by:

Michael Kreuter,

University of Heidelberg, Germany

Reviewed by:

Gunnar N. Hillerdal,

Karolinska University

Hospital, Sweden

Yong-hua Gao,

First Affiliated Hospital of Zhengzhou

University, China

${ }^{*}$ Correspondence:

Kerri l. Aronson

kia9010@med.cornell.edu

Specialty section:

This article was submitted to

Pulmonary Medicine,

a section of the journal

Frontiers in Medicine

Received: 22 July 2021

Accepted: 31 August 2021

Published: 06 October 2021

Citation:

Aronson Kl and Suzuki A (2021)

Health Related Quality of Life in

Interstitial Lung Disease: Can We Use

the Same Concepts Around the

World? Front. Med. 8:745908.

doi: 10.3389/fmed.2021.745908 communities we must recognize that there are differences in the concepts of HRQOL across the world and have strategies to address these differences. In this review, we will describe the different global influences on HRQOL both generally and in the context of ILD, discuss the processes of linguistic translation and cross-cultural adaptation of HRQOL Patient Reported Outcome Measures (PROMs), and highlight the gaps and opportunities for improving HRQOL measurement in ILD across the world.

Keywords: HRQOL-health-related quality of life, interstitial lung disease, global, cross cultural adaptation, linguistic validation

\section{INTRODUCTION}

Health-related quality of life (HRQOL), or one's quality of life as it relates to health status or disease, is increasingly recognized as an important patient centered-outcome by leading health organizations $(1,2)^{1}$. HRQOL is a subjective, dynamic, and multidimensional concept that includes domains representative of an individual patients' goals, values, and beliefs $(3,4)$. Over the past several decades, various conceptual models of HRQOL have contributed to our study of HRQOL in human disease $(2,5-7)$. These models provide an essential structure for conceptualization of HRQOL, including both the positive and negative aspects, and are often used as a guide for research and practices that promote improved HRQOL in different populations of interest (8). HRQOL frameworks most commonly focus on the physical and psychosocial impacts of health or disease on an individual's ability to live what they consider to be a fulfilling life (9). HRQOL amongst those who share the same or different chronic diseases is often very personal and subjective. This subjectivity will vary even more depending on a person's cultural background and environment. The various domains of HRQOL (e.g., psychosocial, physical etc.) that we intend to measure therefore should ideally be considered in the context of an individual's culture and value system

\footnotetext{
${ }^{1}$ Population Assessment of Health-Related Quality of Life.
} 
$(10,11)$. This adds a level of complexity to measurement of HRQOL as we are compelled to recognized that these constructs will differ across different cultural, religious, and socioecological contexts (12). The processes of linguistic and cross-cultural adaptation have allowed for improved measurement of HRQOL across different cultures and languages.

During the past decade, HRQOL has gained much traction as a priority endpoint in the Interstitial Lung Disease (ILD) community. ILD is a group of heterogeneous parenchymal lung diseases with various clinical courses, many of which may be progressive, fibrotic, life altering, and eventually fatal $(13,14)$. Patients and ILD experts alike have vocalized the importance prioritizing HRQOL as a top area of focus in research studies and clinical practice $(15,16)$. Though a few therapies are documented to slow progression of disease [as measured by forced vital capacity (FVC)] in idiopathic pulmonary fibrosis (IPF) and the progressive fibrotic form of other ILDs, there is now much interest in how our interventions effectively slow deterioration in $\operatorname{HRQOL}(17,18)$.

Patient Reported Outcome Measures (PROMs) that measure HRQOL gather information directly from the patient (without interpretation by a clinician or anyone else) about their perspective of the quality of their life in the context of their disease and it's treatments $(19,20)$. There are several PROMs that have undergone validation testing to measure HRQOL in ILD. The most commonly used instruments in the past few decades were originally intended for use in other respiratory diseases, while a handful of newer instruments have been developed for use specifically in ILD and pulmonary fibrosis (21). These "condition" or "disease-specific" PROMs are intended to capture more nuanced information about the impact of living with ILD that is most pertinent to patients with this particular chronic respiratory disease (e.g., breathlessness, cough, fatigue, aspects of psychological well-being) (22). Despite the ILD-targeted items in these instruments, one must be cognizant of the interpretation of the wording of these items for those from other cultures or countries in which the instrument was not developed. For example, dyspnea, or breathlessness is a common ILD symptom that impacts HRQOL. There are various qualitative aspects of this symptom are interpreted differently across different languages and cultures (23-25).

Here we introduce the concept of measuring HRQOL around the world, and as it pertains to specifically to ILD with a focus on linguistics, regional and environmental factors, health literacy and health-care systems, and race, ethnicity, religion and spirituality. We will describe the process of cross-cultural adaptation, the work that has been performed to cross-culturally validate PROMs in ILD, and the potential challenges and opportunities for the future study of HRQOL in ILD on a global scale.

\section{GLOBAL INFLUENCES ON HRQOL}

HRQOL generally reflects each individual's perspective on their own health and is widely accepted as one of the most important patient-centered outcomes. HRQOL measures the impact a chronic disease and its treatment have on several domains of one's life and is largely influenced by cultural and spiritual backgrounds. Therefore, it is expected that the concept of HRQOL will differ across communities within a nation, as well as between countries. Given the growing number of international clinical trials and large population health studies it is increasingly important to recognize the global factors that influence accurate measurement of HRQOL, and how to potentially address them. This section focuses on general considerations for assessing HRQOL in chronic illness, which is pertinent when we consider measurement in ILDs.

\section{Language Diversity}

Linguistic differences are an important consideration when measuring HRQOL. Historically, most HRQOL instruments have been developed in the English Language. Over the past few decades, various HRQOL scales have been internationally translated and standardized across different languages. Translation approaches are traditionally performed by qualified academicians or language experts. With advancements in technology, online translation has also been made available. Despite the availability, convenience, and cost effectiveness of online translation (e.g., google translate), there is controversy related to the validity of this approach when used as the sole method of translation. It has been suggested that if one were to consider using an online program, a more valid approach is a hybrid method with traditional translation by experts with high-level degrees in linguistics in combination with an online program (26). Whatever approach is chosen, researchers must ultimately decide on the translation and adaptation procedures that are most appropriate for their scope of work with consideration of time constraints and available resources.

In order to use a HRQOL instrument appropriately in a new country or culture, the instrument must not only possess linguistic equivalence, but must also capture the cultural differences in disease expression and perception of HRQOL $(27,28)$. We will expand upon this process of "cross cultural adaptation" later in this review.

\section{Regional and Environmental Differences}

An individual's region of origin and environmental context are important considerations during HRQOL assessment. The built environment, defined as the space in which people spend their time in daily life (e.g., home, neighborhood, transportation, or workplace), is closely associated with their health status (29). Seasonal and weather conditions affect physical activity and psychological states (e.g., winter season, unfavorable weather, or decreased sunlight exposure vs. the more positive alternative) (30). Air pollution represented by particulate matter $\left(\mathrm{PM}_{2.5}\right)$ is associated with increased respiratory symptoms and worsened HRQOL $(31,32)$. There is also evidence to suggest that habitat may influence HRQOL. For example, there are reported differences in HRQOL scores between those in rural vs. urban environments (33-36). These environmental contextual factors may play a role in our interpretation of HRQOL scores amongst different populations and more work is needed to formulate an approach to addressing this 
issue. Few clinical studies have corrected for the various potential regional and environmental effects on HRQOL, and this is an important area of potential investigation in the future.

\section{Health Literacy and Diversity of Healthcare Systems}

Health literacy is defined as the ability to access, understand, and effectively use health information $(37,38)$. Patients with low health literacy have less of an understanding about their medical conditions and treatments. This is associated with the potential to worsen health status and disease outcomes (39, 40). A recent study revealed that older age, higher body mass index, residence far from medical institutions, lower monthly income, and lower education levels are associated with a lower health literacy (41). The access to primary care systems and the presence of reliable, understandable, and comprehensive native language medical information websites also contribute to global differences in health literacy (42). The same intervention for a particular chronic disease may be interpreted differently by two patients depending on their comprehension, which may drastically impact patient decision making. Healthcare professionals have made a large effort to improve the impact of low health literacy, including establishment of universal education systems, but many inequalities still exist (42). While mobile health applications may help to enhance interactive patient-provider communication, there is more investigation needed to creatively adapt this technology for use in more remote and resource-limited parts of the world $(17,43-45)$.

\section{Race, Ethnicity, Religion, and Spirituality}

There is a growing body of literature that reveals the association between race, ethnicity, religion, spirituality and HRQOL. A recent study showed that racial and ethnic differences were associated with differences in HRQOL even within the same community (46). If the prevalence of a certain chronic disease is low in a particular race or ethnic group, the negative impact on HRQOL may become greater (47). A lack of familiarity with a chronic disease in a patient's community may lead to social discrimination, with a negative downstream impact on HRQOL (48). A systematic review focused on the relationship between religiosity/spirituality and quality of life (QOL) in patients with cardiovascular disease found a positive association between mental and emotional well-being, spiritual well-being, intrinsic religiousness, and frequency of church attendance (49). While it is important to recognize that these factors play an important role in HRQOL, there is controversy over the extent to which patients should be subdivided by spiritual and religious beliefs for clinical and epidemiological research (50). In order to address these differences, one potential approach is to focus on the longitudinal relative changes in each individual's HRQOL score, rather than comparing cross-sectional absolute values between different patients, but more work is needed to better define and operationalize this approach.

\section{CROSS CULTURAL ADAPTATION}

In the past several decades, the measurement of HRQOL has garnered significant attention as an important endpoint in clinical trials and public health research (51). With the increasing number of multi-country, multi-center trials that are conducted in clinical research there is a growing need for HRQOL measures that can be administered in countries with various languages of origin and amongst different cultural groups where disease expression and health-care system usage may vary (52). In order to administer an HRQOL instrument appropriately in a new country or culture, the instrument must not only possess linguistic equivalence, but must also capture the cultural differences in disease expression and perception of HRQOL $(27,28)$. This allows investigators to collect accurate information about HRQOL of the whole population in one study (when several countries are represented) and to compare results across different studies both nationally and internationally (53). Development of a new PROM is a rigorous and time intensive process (20). It may take years to gather enough data to prove the instrument possesses adequate validity to use in a clinical trial, often with stringent regulatory approval criteria that must be met (54). Rather than develop a brand-new instrument for each distinct language and culture, current practice is to perform "cross cultural adaptation." This process facilitates the translation of existing and wellvalidated instruments in a manner that allows the instrument to retain its psychometric properties in a culturally distinct population (55).

There is overwhelming agreement that an instrument should not be simply translated word for word into another linguistic context, as this can compromise the cultural integrity and equivalence of the findings (56). However, there is not a standardized protocol for linguistic validation or cross cultural adaptation, therefore risking poor translation and compromised research data $(57,58)$.

Several approaches to cross cultural adaptation have been suggested with the goal of maximizing validity and reliability of the instrument that is to be translated into the "target" (or new) language. The Translation and Cultural Adaptation Group (TCA) of the International Society for Pharmacoeconomics and Outcomes Research (ISPOR) task force put forth recommendations for translation and cultural adaptation of PROs in the research community based upon review of the literature and multidisciplinary expert consensus (59). Their recommended approach includes stages of translation and validations testing that require both forward and backwards translation, harmonization that allows for concept equivalence between the source and target language versions of the instrument, review by an expert committee, and cognitive debriefing to assess comprehensibility and cognitive equivalence of the translation by interviewing patients from the target population $(60,61)$. While the ISPOR task force guidelines provide a rigorous approach to translation, they provide less guidance on further psychometric testing to perform beyond translation and assessment of content validity. 
In 1991, the international quality of life assessment (IQOLA) project was established to translate and validate the shortform 36-item health survey (SF-36) (28, 62, 63). The IQOLA project group guidelines encompass a three-stage process that incorporates further psychometric testing; (1) rigorous translation and evaluation process, (2) formal psychometric testing of the assumptions underlying item scoring and construction of multi-item scales, and (3) studies evaluating the equivalence of interpretations across countries $(64,65)$. Their project with the SF-36 transferred an existing generic HRQOL questionnaire to another culture, a process termed "sequential development". On the other hand, in 1990s, the World Health Organization (WHO) developed the WHO Quality of Life assessment instrument (WHOQOL) simultaneously in fifteen different centers worldwide (2). This type of approach helps to ensure equivalence of concepts at each stage as the questionnaire is developed in multiple languages at the same time, a process termed "simultaneous development". In the 1980-1990s, the European Organization for Research and Treatment of Cancer (EORTC) and the EuroQol Group developed the quality of life questionnaire (QLQ-C30), and the EuroQol-5 dimensions (EQ$5 \mathrm{D})$, respectively (66-68). These questionnaires were generated in one language and then forward and backward translated into multiple languages by multinational discussions, a "parallel development" approach. With these historical developments, various HRQOL questionnaire translations are available for clinical trials, daily clinical practice, population studies, and health economic evaluations around the world.

\section{CROSS CULTURAL ADAPTATION IN ILD}

Several patient-reported outcome measures (PROMs) have been adapted for use in ILDs. The PROMs utilized in ILD research and practice are mainly categorized into three groups: (1) disease-specific HRQOL, (2) generic HRQOL, and (3) domainspecific instruments (69). These instruments are ideally chosen as endpoints in research according to the objective of the study and characteristics of the study population. Each of the most common PROMs administered in ILD are at different stages of validation, translation, cross-cultural adaptation, and level of use in clinical trials (Table 1). Here we provide an overview of the current state of cross-cultural adaptation of PROMs in ILD.

\section{Disease-Specific HRQOL PROMs}

Disease-specific HRQOL PROMs in ILD often provide information about the impact of the patient's lung disease on their quality of life. The St George's Respiratory Questionnaire (SGRQ), which was originally developed for patients with chronic obstructive pulmonary diseases (COPD), is one of the most extensively used PROMs for patients with ILDs (70-92). The SGRQ is relatively well-validated in ILD, however there are concerns regarding the applicability of several of the items to patients with ILD. While the SGRQ length and complicated scoring algorithm may pose some challenges for use in daily clinical practice, it has been translated into a wide range of languages making it a potentially attractive option when conducting multinational studies. The cross-sectional reliability of an IPF-specific version of SGRQ (SGRQ-I), has been reported for patients with IPF, however longitudinal data, language translations, and experiences in clinical trials are limited $(93,94)$. The COPD Assessment Test (CAT) is a short and simple questionnaire developed for COPD and is reported to correlate well with the SGRQ in IPF and connective tissue disease-associated ILD (CTD-ILD), but experiences in clinical trials is limited (96-98). The King's Brief ILD (K-BILD), is a disease-specific instrument developed in the UK for use in ILD and has been tested in patients with a large number of ILDs (99-102). There is translation and cultural adaptation data for the K-BILD available for several European and South American countries $(149,150)$, and it is available in multiple languages for use across the globe. Additionally, A tool to Assess the quality of life in Idiopathic Pulmonary Fibrosis (ATAQ-IPF) which was developed initially in the United States to measure HRQOL in Pulmonary Fibrosis has published data on reliability and validity in Chinese patients (cATAQ-IPF) $(105,151)$.

The Living with IPF questionnaire (L-IPF) (107), developed in the English language, has published initial validation data in a cohort of patients with IPF and has recently expanded applicability as the Living with Pulmonary Fibrosis questionnaire (L-PF) (108). The Patient Experiences and Satisfaction with Medications questionnaire (PESaM) is a unique instrument evaluating patients' expectations, experiences, and satisfaction with disease-modifying drugs $(109,110)$. This instrument was developed in the Netherlands and provides systematic evaluation of patient experiences and expectations that may allow for improved shared-decision making. For these more newly developed instruments, more data is needed on the applicability across different languages and cultures.

\section{Generic HRQOL PROMs}

Generic HRQOL measures are designed to assess the overall health status across the general population, regardless of a specific type of chronic disease that one may have. Many of these instruments have been well-translated into a wide range of languages and well-validated in various ways as mentioned above. These instruments allow us to compare the health status between patients with different chronic diseases and healthy people. They are valued as key secondary endpoints in many clinical trials.

The SF-36 is the most widely used generic HRQOL measure. The validity of the SF-36 in ILDs has been established since the 1990s, with various studies reporting the cross-sectional and longitudinal validity in IPF, and has been used in many clinical trials of patients with $\operatorname{ILD}(73,80,81,86,90,119,137-141)$. As the minimal clinically importance difference (MCID) for the SF-36 in IPF varies depending on the cohort, further global validation studies are required. The EuroQol-5 dimensions 5-level (EQ-5D5L) is also a well-known and widely-translated generic HRQOL measure. EQ-5D-5L was developed by the EuroQol Group to improve the instrument's sensitivity as compared with the previous version $(142,143)$. The scores obtained from EQ-5D5L can be used to calculate quality-adjusted life years (QALY), a generic measure of disease burden. QALY measurements enable investigators to assess both the quality and the quantity of life lived and to examine the value of medical interventions (144). 
TABLE 1 | Cross-cultural adaptation and linguistic validation of PROMs in ILD.

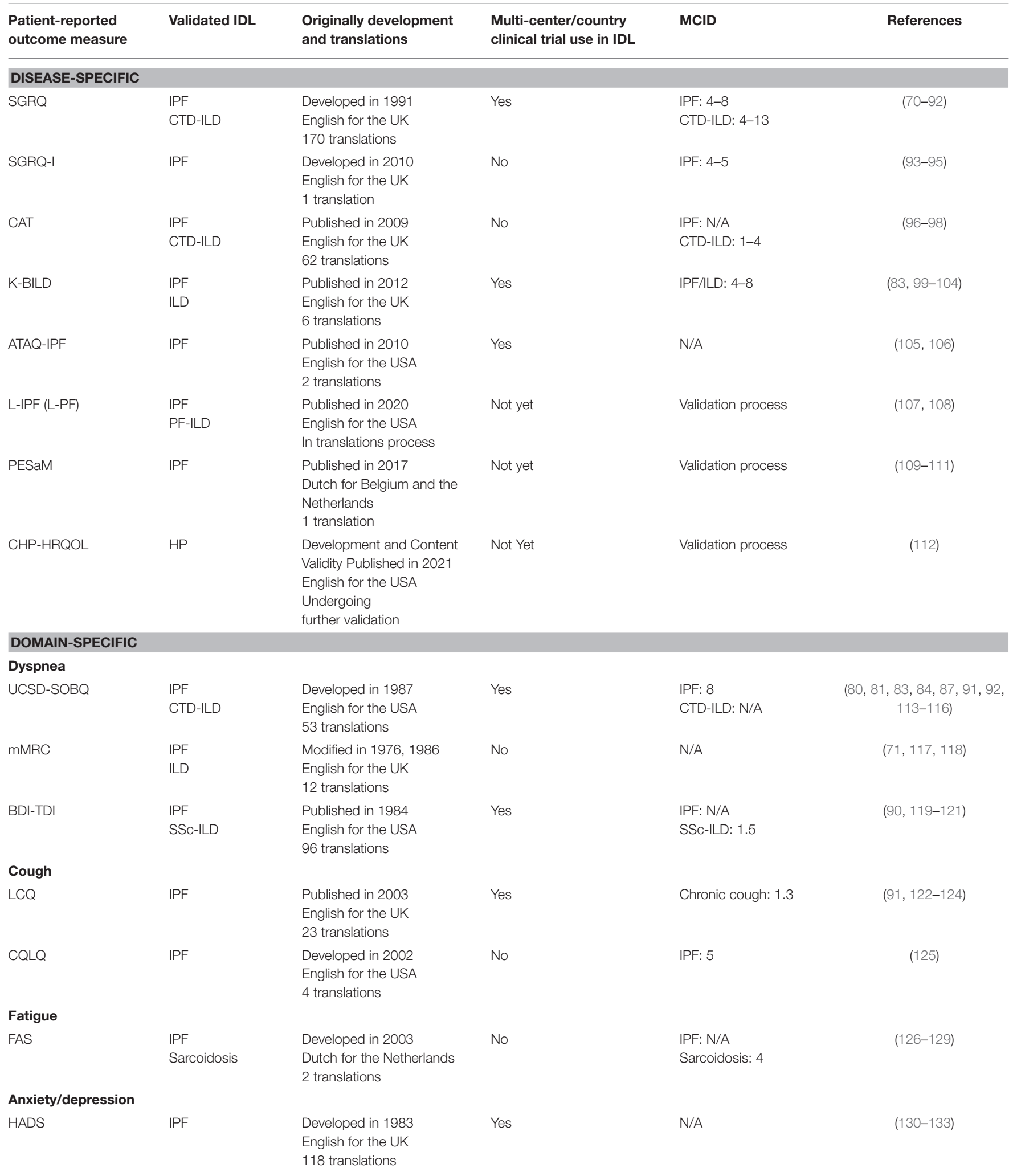


TABLE 1 | Continued

\begin{tabular}{|c|c|c|c|c|c|}
\hline $\begin{array}{l}\text { Patient-reported } \\
\text { outcome measure }\end{array}$ & Validated IDL & $\begin{array}{l}\text { Originally development } \\
\text { and translations }\end{array}$ & $\begin{array}{l}\text { Multi-center/country } \\
\text { clinical trial use in IDL }\end{array}$ & MCID & References \\
\hline \multicolumn{6}{|l|}{ Sleep disorders } \\
\hline EQ-5D-5L & ILD & $\begin{array}{l}\text { Developed in } 2011 \\
\text { Dutch for the Netherlands, } \\
\text { English for the UK, Finnish } \\
\text { for Finland, Norwegian for } \\
\text { Norway, Swedish for } \\
\text { Sweden } \\
181 \text { translations }\end{array}$ & Yes (including EQ-5D) & ILD: 0.005-0.095 & $(142-145)$ \\
\hline PROMIS-29 & $\begin{array}{l}\text { IPF } \\
\text { SSC-ILD }\end{array}$ & $\begin{array}{l}\text { Published in } 2005 \\
\text { English for the USA } \\
47 \text { translations }\end{array}$ & Not yet & N/A & $(146-148)$ \\
\hline
\end{tabular}

ATAQ-IPF, A Tool to Assess Quality of life in IPF; BDI-TDI, Baseline Dyspnea Index-Transition Dyspnea Index; CAT, Chronic obstructive pulmonary disease Assessment Test; CHPHRQOL, Chronic Hypersensitivity Pneumonitis Health Related Quality of Life; CQLQ, Cough Quality of Life Questionnaire; CTD-ILD, connective tissue disease associated interstitial lung

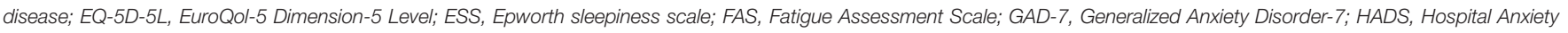

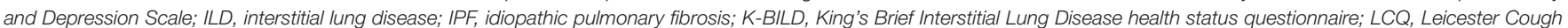

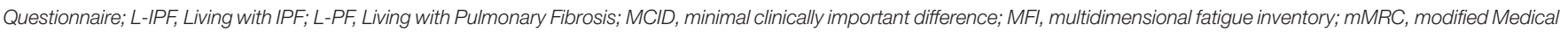

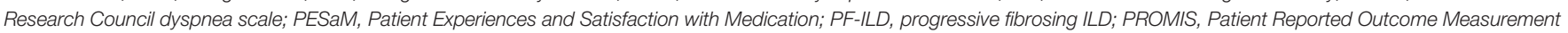

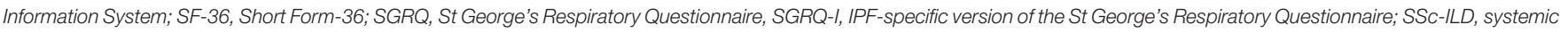
sclerosis related interstitial lung disease; UCSD-SOBQ, University of California San Diego-Shortness of Breath Questionnaire.

The number of translations was referred from ePROVIDETM from MAPI RESEARCH TRUST (https://eprovide.mapi-trust.org) and EQ-5D from EuroQol group (https://euroqol.org).

A recent large cohort study demonstrated the construct validity and MCID of EQ-5D-5L in patients with a variety of fibrotic ILD subtypes (145). The Patient-Reported Outcomes Measurement Information System (PROMIS) is a research initiative launched by the National Institutes of Health to develop the PROMs for clinical research and practice across a wide variety of chronic diseases (146). Some studies have shown that PROMIS29 accurately reflects the deficit in HRQOL of patients with IPF and systemic sclerosis-associated ILD (SSc-ILD), but it is still not widely used in the field of ILD $(147,148)$.

\section{Domain-Specific PROMs}

Domain-specific PROMs focus heavily on specific symptoms that patients may experience, which in ILD often include dyspnea, cough, fatigue, anxiety/depression, and sleep disturbance. While these PROMs do not measure HRQOL per say, they are important to mention as we know that many of these physical and psychologic symptoms are larger drivers of HRQOL in ILD. Among these, dyspnea and cough are most often assessed in ILD studies.

The University of California San Diego-Shortness of Breath Questionnaire (UCSD-SOBQ), the modified Medical Research Council dyspnea scale (mMRC), the Baseline Dyspnea IndexTransition Dyspnea Index (BDI-TDI), and the dyspnea-12 (D12) are common questionnaires administered to assess dyspnea in ILD. The UCSD-SOBQ has been administered in different ILD clinical trials and is well-translated in other languages aside from English. The MCID for IPF has been assessed (80, 81, $83,84,87,91,92,113-116)$. The mMRC is a simple and easy tool for use in daily clinical practice and is reported as a useful predictor of mortality. Experience administering the mMRC in clinical trials and the number of linguistic translations is limited $(71,117,118)$. The BDI-TDI assesses both baseline and change measures over time. It is well-translated into multiple languages, however there is little reported experience in clinical trials $(90,119-121)$. The D-12 is a brief and reliable instrument with positive validation data in ILDs but experience in clinical trials and the number of linguistic translations are limited (113, 152, 153).

The Leicester Cough Questionnaire (LCQ) and the Cough Quality of Life Questionnaire (CQLQ) have been used to assess severity, frequency, and impact of cough in patients with ILD. LCQ is a reliable and relatively easy to complete measure, and there is some experience using it in clinical trials. The responsiveness and MCID are not yet reported in ILD (91, 122124). CQLQ is a comprehensive and responsive measure, and has good cross-sectional validity in IPF, however our experience using this questionnaire in ILD is still limited (125). More studies are needed to assess the validity of cross-culturally adapted versions of these instruments. 


\section{REMAINING GAPS AND OPPORTUNITIES}

Despite the great strides that have been made to highlight the importance of HRQOL in ILD in the past two decades, there are still many opportunities to internationally and cross culturally improve its measurement. The ILD-specific HRQOL questionnaires (e.g., K-BILD, ATAQ-IPF, or L-IPF/L-PF) are designed to measure the nuanced impacts of ILD on HRQOL more precisely than generic instruments. A limited number of translations and cross-cultural adaptations have been performed on these instruments making them less generalizable for use in a larger international study compared to others that may be less ILD specific, but have been around longer and are more widely established (99-102, 105, 107, 108, 149). For example, questionnaires developed for COPD (e.g., SGRQ) are not specific to ILD, but have a large number of translations and are relativelywell-validated in ILD (70-92). More studies are needed to continue to linguistically validate and cross culturally adapt the new ILD disease-specific instruments. To standardize this process internationally, it will require global consensus and a collaborative approach (95).

There is little information on the international equivalence of the methods we use to validate PROMs, e.g., how we calculate internal consistency, construct validity including correlation with other parameters, and responsiveness. The various global concepts that impact HRQOL have the potential to affect the interpretation of PROMs. These diversities may contribute to different interpretation of the items in a single questionnaire amongst various communities and countries. Although no formal method has been established to address this possibility, subgroup analyses of multinational clinical trials may support the validity of each questionnaire across these communities and nations if similar results are obtained (154-156). We must also recognize that a PROM is ideally chosen to measure a certain outcome based upon the context and objective of the research study. This means that one questionnaire that is deemed appropriate for one trial design may not be the same questionnaire that is ideal for another, even if they are both measuring HRQOL. This adds another layer of complexity for multi-national studies as one must not only choose an instrument that will capture information about HRQOL in multiple languages and cultures, but they must also be comfortable that the instrument is measuring the constructs that are important to answer their particular question.

To date, trials testing medications developed for use in fibrotic ILDs have overwhelmingly targeted the halt of disease progression as reflected by pulmonary function, exercise tolerance, or progression-free survival $(82,103,115,157)$. As disease-specific HRQOL PROMs generally reflect changes in these parameters, these have characteristically been chosen for use in those clinical trials $(77,98,100)$. As patient-centered research in ILD expands, future interventions may target the more disease-specific symptoms (e.g., cough, dyspnea, fatigue) (158-160). For these clinical trials, domain-specific PROMs focusing on each symptom may likely be chosen as the primary endpoint and therefore these instruments will need to be adapted for use cross-culturally.

The guidelines for development of PROMs are not internationally unified. Regulatory agencies such as the US Food and Drug Administration (FDA) and the European Medicines Agency (EMA) have released PROM development guidance as we increasingly recognize the importance of including these measures in clinical trials $(161,162)$. Recent PROMs including the K-BILD and L-IPF/L-PF adhered strictly to their guidelines during the process of developments $(99,107)$. Although there is no question that these guidelines are well-established and rigorous, it is necessary to verify whether the same methodology can be adapted in non-English speaking countries where there are different cultural components as well as potentially different resources available.

Finally, we need to consider the international inequalities of HRQOL itself. As discussed in this review, many individual factors are closely associated with a patient's health status. In fact, the global burdens of ILD measured by disability-adjusted life years (DALYs), which is calculated as the number of years lost due to disability or early death, are known to greatly vary across the countries (163). The level of HRQOL impairment may differ in each country, even if the disease severity assessed by pulmonary function is the same. Therefore, an understanding of the baseline health status in any individual country is important. If there is a large difference in the baseline health status between groups, then the evaluation of relative change in each individual or group should be considered. Multinational consortia of researchers with expertise in PROMs and who study HRQOL are needed in order to begin to address some of these gaps on an international level.

\section{CONCLUSION}

HRQOL is an increasingly important end point in ILD amongst patients, clinicians, and researchers alike. As our understanding of the disease and its possible therapies expands, we are rapidly accelerating opportunities for clinical trial conduct across the globe. While we have made great strides in the measurement of HRQOL in ILD, we have many opportunities to improve our measurement across cultures and countries. We have identified several ways in which HRQOL may be interpreted differently across the globe and highlighted potential mechanisms for translation and cross-cultural adaptation of HRQOL PROMs, both in general and in ILD. By recognizing these important differences and working together with our colleagues and patients across the globe we have the opportunity to improve the way we study and report HRQOL which will have a substantial impact on the conduct of multinational studies and interventions in the future.

\section{AUTHOR CONTRIBUTIONS}

KA and AS contributed equally to the conception and writing of this manuscript. Both authors contributed to the article and approved the submitted version. 


\section{REFERENCES}

1. Institute of Medicine. The Future of the Public's Health in the 21st Century. Washington, DC: National Academies Press (US) (2002).

2. The WHOQOL Group. The World Health Organization Quality of Life assessment (WHOQOL): position paper from the World Health Organization. Soc Sci Med. (1995) 41:1403-9. doi: 10.1016/0277-9536(95)00112-K

3. Skevington SM, Lotfy M, O'Connell KA. The World Health Organization's WHOQOL-BREF quality of life assessment: psychometric properties and results of the international field trial. A Report from the WHOQOL Group. Qual Life Res. (2004) 13:299-310. doi: 10.1023/B:QURE.0000018486.91360.00

4. The World Health Organization Quality of Life Assessment (WHOQOL): development and general psychometric properties. Soc Sci Med. (1998) 46:1569-85. doi: 10.1016/S0277-9536(98)00009-4

5. Wilson IB, Cleary PD. Linking clinical variables with health-related quality of life. a conceptual model of patient outcomes. JAMA. (1995) 273:59-65. doi: 10.1001/jama.273.1.59

6. Ferrans CE, Zerwic JJ, Wilbur JE, Larson JL. Conceptual model of health-related quality of life. J Nurs Scholarsh. (2005) 37:336-42. doi: 10.1111/j.1547-5069.2005.00058.x

7. Burckhardt CS, Anderson KL, Archenholtz B, Hägg O. The Flanagan Quality Of Life Scale: evidence of construct validity. Health Qual Life Outcomes. (2003) 1:59. doi: 10.1186/1477-7525-1-59

8. Bakas T, McLennon SM, Carpenter JS, Buelow JM, Otte JL, Hanna KM, et al. Systematic review of health-related quality of life models. Health Qual Life Outcomes. (2012) 10:134. doi: 10.1186/1477-7525-10-134

9. Haraldstad K, Wahl A, Andenæs R, Andersen JR, Andersen MH, Beisland E, et al. A systematic review of quality of life research in medicine and health sciences. Qual Life Res. (2019) 28:2641-50. doi: 10.1007/s11136-019-02214-9

10. O'Connell KA, Skevington SM. To measure or not to measure? Reviewing the assessment of spirituality and religion in health-related quality of life. Chronic Illn. (2007) 3:77-87. doi: 10.1177/1742395307079195

11. O'Connell KA, Skevington SM. The relevance of spirituality, religion and personal beliefs to health-related quality of life: themes from focus groups in Britain. Br J Health Psychol. (2005) 10(Pt 3):379-98. doi: 10.1348/135910705X25471

12. Ashing-Giwa KT. The contextual model of HRQoL: a paradigm for expanding the HRQoL framework. Qual Life Res. (2005) 14:297-307. doi: 10.1007/s11136-004-0729-7

13. Cottin V, Hirani NA, Hotchkin DL, Nambiar AM, Ogura T, Otaola M, et al. Presentation, diagnosis and clinical course of the spectrum of progressivefibrosing interstitial lung diseases. Eur Respir Rev. (2018) 27:180076. doi: $10.1183 / 16000617.0076-2018$

14. Kolb $\mathrm{M}$, Vašáková $\mathrm{M}$. The natural history of progressive fibrosing interstitial lung diseases. Respir Res. (2019) 20:57. doi: 10.1186/s12931-019-1022-1

15. Bajwah S, Colquitt J, Loveman E, Bausewein C, Almond H, Oluyase A, et al. Pharmacological and nonpharmacological interventions to improve symptom control, functional exercise capacity and quality of life in interstitial lung disease: an evidence synthesis. ERJ Open Res. (2021) 7:00107-2020. doi: 10.1183/23120541.00107-2020

16. Lammi MR, Baughman RP, Birring SS, Russell A-M, Ryu JH, Scholand $M$, et al. Outcome measures for clinical trials in interstitial lung diseases. Curr Respir Med Rev. (2015) 11:163-74. doi: 10.2174/1573398X11666150619183527

17. Rajala K, Lehto JT, Sutinen E, Kautiainen H, Myllärniemi M, Saarto T. Marked deterioration in the quality of life of patients with idiopathic pulmonary fibrosis during the last two years of life. BMC Pulm Med. (2018) 18:172. doi: 10.1186/s12890-018-0738-x

18. Brown KK, Martinez FJ, Walsh SLF, Thannickal VJ, Prasse A, SchlenkerHerceg R, et al. The natural history of progressive fibrosing interstitial lung diseases. Eur Respir J. (2020) 55:2000085. doi: 10.1183/13993003.00085-2020

19. Kingsley C, Patel S. Patient-reported outcome measures and patient-reported experience measures. BJA Educ. (2017) 17:137-44. doi: 10.1093/bjaed/mkw060

20. Food and Drug Administration. Guidance For Industry Patient-Reported Outcome Measures: Use in Medical Product Development to Support
Labeling Claims. (2009). Available online at: https://www.fda.gov/media/ 77832/download (accessed 29, 2020).

21. Swigris JJ, Brown KK, Abdulqawi R, Buch K, Dilling DF, Koschel D, et al. Patients' perceptions and patient-reported outcomes in progressivefibrosing interstitial lung diseases. Eur Respir Rev. (2018) 27:180075. doi: 10.1183/16000617.0075-2018

22. Moor CC, Heukels P, Kool M, Wijsenbeek MS. Integrating patient perspectives into personalized medicine in idiopathic pulmonary fibrosis. Front Med. (2017) 4:226. doi: 10.3389/fmed.2017.00226

23. O'Donnell DE, Chau LK, Webb KA. Qualitative aspects of exertional dyspnea in patients with interstitial lung disease. J Appl Physiol. (1998) 84:2000-9. doi: 10.1152/jappl.1998.84.6.2000

24. Smith J, Albert P, Bertella E, Lester J, Jack S, Calverley P. Qualitative aspects of breathlessness in health and disease. Thorax. (2009) 64:713-8. doi: 10.1136/thx.2008.104869

25. Vázquez-García JC, Balcázar-Cruz CA, Cervantes-Méndez G, MejíaAlfaro R, Cossío-Alcántara J, Ramírez-Venegas A. [Descriptors of breathlessness in Mexican Spanish]. Arch Bronconeumol. (2006) 42:211-7. doi: 10.1016/S1579-2129(06)60448-5

26. Goyal AK, Bakshi J, Panda NK, Kapoor R, Vir D, Kumar K, et al. A hybrid method for the cross-cultural adaptation of self-report measures. Int J Appl Posit Psychol. (2021) 6:45-54. doi: 10.1007/s41042-020-00039-3

27. Chakka S, Werth VP. Cross-cultural adaptations of health-related quality of life measures. Br J Dermatol. (2019) 181:659-60. doi: 10.1111/bjd.18272

28. Beaton DE, Bombardier C, Guillemin F, Ferraz MB. Guidelines for the process of cross-cultural adaptation of self-report measures. Spine. (2000) 25:3186-91. doi: 10.1097/00007632-200012150-00014

29. Roof K, Oleru N. Public health: seattle and King County's push for the built environment. J Environ Health. (2008) 71:24-7.

30. Tucker P, Gilliland J. The effect of season and weather on physical activity: a systematic review. Public Health. (2007) 121:909-22. doi: 10.1016/j.puhe.2007.04.009

31. Pirozzi CS, Mendoza DL, Xu Y, Zhang Y, Scholand MB, Baughman RP. Short-term particulate air pollution exposure is associated with increased severity of respiratory and quality of life symptoms in patients with fibrotic sarcoidosis. Int J Environ Res Public Health. (2018) 151077. doi: 10.3390/ijerph15061077

32. Han B. Associations between perceived environmental pollution and healthrelated quality of life in a Chinese adult population. Health Qual Life Outcomes. (2020) 18:198. doi: 10.1186/s12955-020-01442-9

33. Zhou Z, Zhou Z, Gao J, Lai S, Chen G. Urban-rural difference in the associations between living arrangements and the health-related quality of life (HRQOL) of the elderly in China-Evidence from Shaanxi province. PLoS ONE. (2018) 13:e0204118. doi: 10.1371/journal.pone.02 04118

34. Zhang T, Shi W, Huang Z, Gao D, Guo Z, Liu J, et al. Influence of culture, residential segregation and socioeconomic development on rural elderly health-related quality of life in Guangxi, China. Health Qual Life Outcomes. (2016) 14:98. doi: 10.1186/s12955-016-0499-2

35. Wang C, Li H, Li L, Xu D, Kane RL, Meng Q. Health literacy and ethnic disparities in health-related quality of life among rural women: results from a Chinese poor minority area. Health Qual Life Outcomes. (2013) 11:153. doi: 10.1186/1477-7525-11-153

36. Sabbah I, Drouby N, Sabbah S, Retel-Rude N, Mercier M. Quality of life in rural and urban populations in Lebanon using SF-36 health survey. Health Qual Life Outcomes. (2003) 1:30. doi: 10.1186/1477-7525-1-30

37. Nutbeam D. The evolving concept of health literacy. Soc Sci Med. (2008) 67:2072-8. doi: 10.1016/j.socscimed.2008.09.050

38. Liu C, Wang D, Liu C, Jiang J, Wang X, Chen H, et al. What is the meaning of health literacy? A systematic review and qualitative synthesis. Family Med Commun Health. (2020) 8:e000351. doi: 10.1136/fmch-2020-000351

39. Health literacy: report of the Council on Scientific. Ad Hoc Committee on Health Literacy for the Council on Scientific Affairs, American Medical Association. JAMA. (1999) 281:552-7.

40. Zheng $\mathrm{M}$, Jin $\mathrm{H}$, Shi $\mathrm{N}$, Duan $\mathrm{C}$, Wang $\mathrm{D}$, Yu $\mathrm{X}$, et al. The relationship between health literacy and quality of life: a systematic review and meta-analysis. Health Qual Life Outcomes. (2018) 16:201. doi: $10.1186 / \mathrm{s} 12955-018-1031-7$ 
41. Xie Y, Ma M, Zhang Y, Tan X. Factors associated with health literacy in rural areas of Central China: structural equation model. BMC Health Serv Res. (2019) 19:300. doi: 10.1186/s12913-019-4094-1

42. Nakayama K, Osaka W, Togari T, Ishikawa H, Yonekura Y, Sekido A, et al. Comprehensive health literacy in Japan is lower than in Europe: a validated Japanese-language assessment of health literacy. BMC Public Health. (2015) 15:505. doi: 10.1186/s12889-015-1835-x

43. Moor CC, van Leuven SI, Wijsenbeek MS, Vonk MC. Feasibility of online home spirometry in systemic sclerosis-associated interstitial lung disease: a pilot study. Rheumatology. (2021) 60:2467-71. doi: 10.1093/rheumatology/keaa607

44. Abolfotouh MA, BaniMustafa A, Salam M, Al-Assiri M, Aldebasi B, Bushnak I. Use of smartphone and perception towards the usefulness and practicality of its medical applications among healthcare workers in Saudi Arabia. BMC Health Serv Res. (2019) 19:826. doi: 10.1186/s12913-019-4523-1

45. Moor CC, Wapenaar M, Miedema JR, Geelhoed JJM, Chandoesing PP, Wijsenbeek MS. A home monitoring program including realtime wireless home spirometry in idiopathic pulmonary fibrosis: a pilot study on experiences and barriers. Respir Res. (2018) 19:105. doi: 10.1186/s12931-018-0810-3

46. Lim E, Davis J, Siriwardhana C, Aggarwal L, Hixon A, Chen JJ. Racial/ethnic differences in health-related quality of life among Hawaii adult population. Health Qual Life Outcomes. (2020) 18:380. doi: 10.1186/s12955-020-01625-4

47. Quittner AL, Schechter MS, Rasouliyan L, Haselkorn T, Pasta DJ, Wagener JS. Impact of socioeconomic status, race, and ethnicity on quality of life in patients with cystic fibrosis in the United States. Chest. (2010) 137:642-50. doi: 10.1378/chest.09-0345

48. Sentell T, Zhang W, Davis J, Baker KK, Braun KL. The influence of community and individual health literacy on self-reported health status. $J$ Gen Intern Med. (2014) 29:298-304. doi: 10.1007/s11606-013-2638-3

49. Abu HO, Ulbricht C, Ding E, Allison JJ, Salmoirago-Blotcher E, Goldberg RJ, et al. Association of religiosity and spirituality with quality of life in patients with cardiovascular disease: a systematic review. Qual Life Res. (2018) 27:2777-97. doi: 10.1007/s11136-018-1906-4

50. Ferrell B, Chung V, Koczywas M, Borneman T, Irish TL, Ruel NH, et al. Spirituality in cancer patients on phase 1 clinical trials. Psychooncology. (2020) 29:1077-83. doi: 10.1002/pon.5380

51. Guyatt GH, Ferrans CE, Halyard MY, Revicki DA, Symonds TL, Varricchio $\mathrm{CG}$, et al. Exploration of the value of health-related quality-of-life information from clinical research and into clinical practice. Mayo Clin Proc. (2007) 82:1229-39. doi: 10.4065/82.10.1229

52. Guillemin F, Bombardier C, Beaton D. Cross-cultural adaptation of healthrelated quality of life measures: literature review and proposed guidelines. $J$ Clin Epidemiol. (1993) 46:1417-32. doi: 10.1016/0895-4356(93)90142-N

53. Herdman M, Fox-Rushby J, Badia X. "Equivalence" and the translation and adaptation of health-related quality of life questionnaires. Qual Life Res. (1997) 6:237-47. doi: 10.1023/A:1026410721664

54. Rothrock NE, Kaiser KA, Cella D. Developing a valid patientreported outcome measure. Clin Pharmacol Ther. (2011) 90:737-42. doi: 10.1038/clpt.2011.195

55. da Mota Falcão D, Ciconelli RM, Ferraz MB. Translation and cultural adaptation of quality of life questionnaires: an evaluation of methodology. J Rheumatol. (2003) 30:379-85.

56. Gjersing L, Caplehorn JRM, Clausen T. Cross-cultural adaptation of research instruments: language, setting, time and statistical considerations. BMC Med Res Methodol. (2010) 10:13. doi: 10.1186/1471-2288-10-13

57. Wang W-L, Lee H-L, Fetzer SJ. Challenges and strategies of instrument translation. West J Nurs Res. (2006) 28:310-21. doi: 10.1177/0193945905284712

58. Sechrest L, Fay TL, Zaidi SMH. Problems of translation in cross-cultural research. J Cross Cult Psychol. (1972) 3:41-56. doi: 10.1177/002202217200300103

59. Wild D, Grove A, Martin M, Eremenco S, McElroy S, Verjee-Lorenz A, et al. Principles of good practice for the translation and cultural adaptation process for Patient-Reported Outcomes (PRO) Measures: report of the ISPOR task force for translation and cultural adaptation. Value Health. (2005) 8:94-104. doi: 10.1111/j.1524-4733.2005.04054.x
60. Hofmeyer A, Sheingold BH, Taylor R. Do you understand what I mean? how cognitive interviewing can strengthen valid, reliable study instruments and dissemination products. J Int Educ Res. (2015) 11:261. doi: 10.19030/jier.v11i4.9460

61. Scott K, Gharai D, Sharma M, Choudhury N, Mishra B, Chamberlain S, et al. Yes, no, maybe so: the importance of cognitive interviewing to enhance structured surveys on respectful maternity care in northern India. Health Policy Plan. (2020) 35:67-77. doi: 10.1093/heapol/czz141

62. Ware JE, Gandek B. Methods for testing data quality, scaling assumptions, and reliability: the IQOLA Project approach. International Quality of Life Assessment. J Clin Epidemiol. (1998) 51:945-52. doi: 10.1016/S0895-4356(98)00085-7

63. Aaronson NK, Acquadro C, Alonso J, Apolone G, Bucquet D, Bullinger M, et al. International quality of life assessment (IQOLA) project. Qual Life Res. (1992) 1:349-51. doi: 10.1007/BF00434949

64. Ware JE, Keller SD, Gandek B, Brazier JE, Sullivan M. Evaluating translations of health status questionnaires. Methods from the IQOLA project. International Quality of Life Assessment. Int J Technol Assess Health Care. (1995) 11:525-51. doi: 10.1017/S0266462300008710

65. Ware JE, Gandek B. Overview of the SF-36 health survey and the International Quality of Life Assessment (IQOLA) project. J Clin Epidemiol. (1998) 51:903-12. doi: 10.1016/S0895-4356(98)00081-X

66. Aaronson NK, Ahmedzai S, Bergman B, Bullinger M, Cull A, Duez NJ, et al. The European Organization for Research and Treatment of Cancer QLQ-C30: a quality-of-life instrument for use in international clinical trials in oncology. J Natl Cancer Inst. (1993) 85:365-76. doi: 10.1093/jnci/8 5.5.365

67. EuroQol Group. EuroQol-a new facility for the measurement of health-related quality of life. Health Policy. (1990) 16:199-208. doi: 10.1016/0168-8510(90)90421-9

68. Devlin NJ, Brooks R. EQ-5D and the EuroQol group: past, present and future. Appl Health Econ Health Policy. (2017) 15:127-37. doi: 10.1007/s40258-017-0310-5

69. Aronson KI, Danoff SK, Russell A-M, Ryerson CJ, Suzuki A, Wijsenbeek MS, et al. Patient-centered Outcomes Research in Interstitial Lung Disease: an Official American Thoracic Society Research Statement. Am J Respir Crit Care Med. (2021) 204:e3-23. doi: 10.1164/rccm.202105-1 193ST

70. Jones PW, Quirk FH, Baveystock CM, Littlejohns P. A self-complete measure of health status for chronic airflow limitation. The St. George's Respiratory Questionnaire. Am Rev Respir Dis. (1992) 145:1321-7. doi: 10.1164/ajrccm/145.6.1321

71. Tzanakis N, Samiou M, Lambiri I, Antoniou K, Siafakas N, Bouros D. Evaluation of health-related quality-of-life and dyspnea scales in patients with idiopathic pulmonary fibrosis. Correlation with pulmonary function tests. Eur J Intern Med. (2005) 16:105-12. doi: 10.1016/j.ejim.2004.09.013

72. Beretta L, Santaniello A, Lemos A, Masciocchi M, Scorza R. Validity of the Saint George's Respiratory Questionnaire in the evaluation of the health-related quality of life in patients with interstitial lung disease secondary to systemic sclerosis. Rheumatology. (2007) 46:296-301. doi: 10.1093/rheumatology/kel221

73. Swigris JJ, Brown KK, Behr J, du Bois RM, King TE, Raghu G, et al. The SF-36 and SGRQ: validity and first look at minimum important differences in IPF. Respir Med. (2010) 104:296-304. doi: 10.1016/j.rmed.2009. 09.006

74. Wallace B, Kafaja S, Furst DE, Berrocal VJ, Merkel PA, Seibold JR, et al. Reliability, validity and responsiveness to change of the Saint George's Respiratory Questionnaire in early diffuse cutaneous systemic sclerosis. Rheumatology. (2015) 54:1369-79. doi: 10.1093/rheumatology/keu456

75. Swigris JJ, Esser D, Wilson H, Conoscenti CS, Schmidt H, Stansen W, et al. Psychometric properties of the St George's Respiratory Questionnaire in patients with idiopathic pulmonary fibrosis. Eur Respir J. (2017) 49:1601788. doi: 10.1183/13993003.01788-2016

76. Glaspole IN, Chapman SA, Cooper WA, Ellis SJ, Goh NS, Hopkins $\mathrm{PM}$, et al. Health-related quality of life in idiopathic pulmonary fibrosis: data from the Australian IPF Registry. Respirology. (2017) 22:950-6. doi: $10.1111 /$ resp. 12989 
77. Suzuki A, Kondoh Y, Swigris JJ, Ando M, Kimura T, Kataoka K, et al. Performance of the St George's Respiratory Questionnaire in patients with connective tissue disease-associated interstitial lung disease. Respirology. (2018). doi: 10.1111/resp.13293. [Epub ahead of print].

78. Kreuter M, Swigris J, Pittrow D, Geier S, Klotsche J, Prasse A, et al. The clinical course of idiopathic pulmonary fibrosis and its association to quality of life over time: longitudinal data from the INSIGHTS-IPF registry. Respir Res. (2019) 20:59. doi: 10.1186/s12931-019-1020-3

79. Swigris JJ, Wilson H, Esser D, Conoscenti CS, Stansen W, Kline Leidy N, et al. Psychometric properties of the St George's Respiratory Questionnaire in patients with idiopathic pulmonary fibrosis: insights from the INPULSIS trials. BMJ Open Respir Res. (2018) 5:e000278. doi: 10.1136/bmjresp-2018-000278

80. Idiopathic Pulmonary Fibrosis Clinical Research Network, Zisman DA, Schwarz M, Anstrom KJ, Collard HR, Flaherty KR, et al. A controlled trial of sildenafil in advanced idiopathic pulmonary fibrosis. N Engl J Med. (2010) 363:620-8. doi: 10.1056/NEJMoa1002110

81. Idiopathic Pulmonary Fibrosis Clinical Research Network, Raghu G, Anstrom KJ, King TE, Lasky JA, Martinez FJ. Prednisone, azathioprine, and $\mathrm{N}$-acetylcysteine for pulmonary fibrosis. N Engl J Med. (2012) 366:1968-77. doi: 10.1056/NEJMoa1113354

82. Richeldi L, du Bois RM, Raghu G, Azuma A, Brown KK, Costabel U, et al. Efficacy and safety of nintedanib in idiopathic pulmonary fibrosis. $\mathrm{N}$ Engl J Med. (2014) 370:2071-82. doi: 10.1056/NEJMoa1402584

83. Visca D, Mori L, Tsipouri V, Fleming S, Firouzi A, Bonini M, et al. Effect of ambulatory oxygen on quality of life for patients with fibrotic lung disease (AmbOx): a prospective, open-label, mixed-method, crossover randomised controlled trial. Lancet Respir Med. (2018) 6:759-70. doi: 10.1016/S2213-2600(18)30289-3

84. Kolb M, Raghu G, Wells AU, Behr J, Richeldi L, Schinzel B, et al. Nintedanib plus Sildenafil in patients with idiopathic pulmonary fibrosis. $N$ Engl J Med. (2018) 379:1722-31. doi: 10.1056/NEJMoa1811737

85. Demedts M, Behr J, Buhl R, Costabel U, Dekhuijzen R, Jansen HM, et al. High-dose acetylcysteine in idiopathic pulmonary fibrosis. $N$ Engl J Med. (2005) 353:2229-42. doi: 10.1056/NEJMoa042976

86. Raghu G, Brown KK, Costabel U, Cottin V, du Bois RM, Lasky JA, et al. Treatment of idiopathic pulmonary fibrosis with etanercept: an exploratory, placebo-controlled trial. Am J Respir Crit Care Med. (2008) 178:948-55. doi: 10.1164/rccm.200709-1446OC

87. King TE, Albera C, Bradford WZ, Costabel U, Hormel P, Lancaster $\mathrm{L}$, et al. Effect of interferon gamma-1b on survival in patients with idiopathic pulmonary fibrosis (INSPIRE): a multicentre, randomised, placebo-controlled trial. Lancet. (2009) 374:222-8. doi: 10.1016/S0140-6736(09)60551-1

88. Han MK, Bach DS, Hagan PG, Yow E, Flaherty KR, Toews GB, et al. Sildenafil preserves exercise capacity in patients with idiopathic pulmonary fibrosis and right-sided ventricular dysfunction. Chest. (2013) 143:1699-708. doi: 10.1378/chest.12-1594

89. Richeldi L, Costabel U, Selman M, Kim DS, Hansell DM, Nicholson AG, et al. Efficacy of a tyrosine kinase inhibitor in idiopathic pulmonary fibrosis. $N$ Engl J Med. (2011) 365:1079-87. doi: 10.1056/NEJMoa1103690

90. Raghu G, Behr J, Brown KK, Egan JJ, Kawut SM, Flaherty KR, et al. Treatment of idiopathic pulmonary fibrosis with ambrisentan: a parallel, randomized trial. Ann Intern Med. (2013) 158:641-9. doi: 10.7326/0003-4819-158-9-201305070-00003

91. Maher TM, Corte TJ, Fischer A, Kreuter M, Lederer DJ, Molina-Molina M, et al. Pirfenidone in patients with unclassifiable progressive fibrosing interstitial lung disease: a double-blind, randomised, placebo-controlled, phase 2 trial. Lancet Respir Med. (2020) 8:147-57. doi: 10.1016/S2213-2600(19)30341-8

92. Behr J, Nathan SD, Wuyts WA, Mogulkoc Bishop N, Bouros DE, Antoniou $\mathrm{K}$, et al. Efficacy and safety of sildenafil added to pirfenidone in patients with advanced idiopathic pulmonary fibrosis and risk of pulmonary hypertension: a double-blind, randomised, placebo-controlled, phase $2 \mathrm{~b}$ trial. Lancet Respir Med. (2021) 9:85-95. doi: 10.1016/S2213-2600(20)3 0356-8

93. Yorke J, Jones PW, Swigris JJ. Development and validity testing of an IPFspecific version of the St George's Respiratory Questionnaire. Thorax. (2010) 65:921-6. doi: 10.1136/thx.2010.139121
94. Prior TS, Hoyer N, Shaker SB, Davidsen JR, Yorke J, Hilberg O, et al. Validation of the IPF-specific version of St. George's Respiratory Questionnaire. Respir Res. (2019) 20:199. doi: 10.1186/s12931-019-1169-9

95. Prior TS, Hoyer N, Hilberg O, Shaker SB, Davidsen JR, Bendstrup E. Responsiveness and minimal clinically important difference of SGRQ-I and K-BILD in idiopathic pulmonary fibrosis. Respir Res. (2020) 21:91. doi: 10.1186/s12931-020-01359-3

96. Jones PW, Harding G, Berry P, Wiklund I, Chen WH, Kline Leidy N. Development and first validation of the COPD Assessment Test. Eur Respir J. (2009) 34:648-54. doi: 10.1183/09031936.00102509

97. Nagata K, Tomii K, Otsuka K, Tachikawa R, Otsuka K, Takeshita $\mathrm{J}$, et al. Evaluation of the chronic obstructive pulmonary disease assessment test for measurement of health-related quality of life in patients with interstitial lung disease. Respirology. (2012) 17:506-12. doi: 10.1111/j.1440-1843.2012.02131.x

98. Suzuki A, Kondoh Y, Swigris JJ, Matsuda T, Kimura T, Kataoka K, et al. Performance of the COPD Assessment Test in patients with connective tissue disease-associated interstitial lung disease. Respir Med. (2019) 150:15-20. doi: 10.1016/j.rmed.2019.01.017

99. Patel AS, Siegert RJ, Brignall K, Gordon P, Steer S, Desai SR, et al. The development and validation of the King's Brief Interstitial Lung Disease (K-BILD) health status questionnaire. Thorax. (2012) 67:804-10. doi: 10.1136/thoraxjnl-2012-201581

100. Nolan CM, Birring SS, Maddocks M, Maher TM, Patel S, Barker RE, et al. King's Brief Interstitial Lung Disease questionnaire: responsiveness and minimum clinically important difference. Eur Respir J. (2019) 54:1900281. doi: 10.1183/13993003.00281-2019

101. Patel AS, Siegert RJ, Keir GJ, Bajwah S, Barker RD, Maher TM, et al. The minimal important difference of the King's Brief Interstitial Lung Disease Questionnaire (K-BILD) and forced vital capacity in interstitial lung disease. Respir Med. (2013) 107:1438-43. doi: 10.1016/j.rmed.2013.06.009

102. Sinha A, Patel AS, Siegert RJ, Bajwah S, Maher TM, Renzoni EA, et al. The King's Brief Interstitial Lung Disease (KBILD) questionnaire: an updated minimal clinically important difference. BMJ Open Respir Res. (2019) 6:e000363. doi: 10.1136/bmjresp-2018-000363

103. Flaherty KR, Wells AU, Cottin V, Devaraj A, Walsh SLF, Inoue $\mathrm{Y}$, et al Nintedanib in progressive fibrosing interstitial lung diseases. $N$ Engl J Med. (2019) 381:1718-27. doi: 10.1056/NEJMoa1908681

104. Wapenaar M, Patel AS, Birring SS, Domburg RT van, Bakker EW, Vindigni $\mathrm{V}$, et al. Translation and validation of the King's Brief Interstitial Lung Disease (K-BILD) questionnaire in French, Italian, Swedish, and Dutch. Chron Respir Dis. (2017) 14:140-50. doi: 10.1177/1479972316674425

105. Swigris JJ, Wilson SR, Green KE, Sprunger DB, Brown KK, Wamboldt FS. Development of the ATAQ-IPF: a tool to assess quality of life in IPF. Health Qual Life Outcomes. (2010) 8:77. doi: 10.1186/1477-7525-8-77

106. Maher TM, Costabel U, Glassberg MK, Kondoh Y, Ogura T, Scholand MB, et al. Phase 2 trial to assess lebrikizumab in patients with idiopathic pulmonary fibrosis. Eur Respir J. (2021) 57:1902442. doi: 10.1183/13993003.02442-2019

107. Swigris JJ, Andrae DA, Churney T, Johnson N, Scholand MB, White ES, et al. Development and initial validation analyses of the living with idiopathic pulmonary fibrosis questionnaire. Am J Respir Crit Care Med. (2020) 202:1689-97. doi: 10.1164/rccm.202002-0415OC

108. Swigris J, Cutts K, Male N, Baldwin M, Rohr KB, Bushnell DM. The Living with Pulmonary Fibrosis questionnaire in progressive fibrosing interstitial lung disease. ERJ Open Res. (2021) 7:00145-2020. doi: 10.1183/23120541.00145-2020

109. Kimman ML, Rotteveel AH, Wijsenbeek M, Mostard R, Tak NC, van Jaarsveld X, et al. Development and pretesting of a questionnaire to assess patient experiences and satisfaction with medications (PESaM Questionnaire). Patient. (2017) 10:629-42. doi: 10.1007/s40271-017-0234-Z

110. Kimman ML, Wijsenbeek MS, van Kuijk SMJ, Wijnsma KL, van de Kar NCAJ, Storm M, et al. Validity of the patient experiences and satisfaction with medications (PESaM) questionnaire. Patient. (2019) 12:149-62. doi: 10.1007/s40271-018-0340-6

111. Moor CC, Mostard RLM, Grutters JC, Bresser P, Aerts JGJV, Dirksen CD, et al. Patient expectations, experiences and satisfaction with nintedanib and pirfenidone in idiopathic pulmonary fibrosis: a quantitative study. Respir Res. (2020) 21:196. doi: 10.1186/s12931-020-01458-1 
112. Aronson KI, Ali M, Reshetynak E, Kaner RJ, Martinez FJ, Safford MM, et al. Establishing content-validity of a disease-specific health-related quality of life instrument for patients with chronic hypersensitivity pneumonitis. J Patient Rep Outcomes. (2021) 5:9. doi: 10.1186/s41687-020-00282-x

113. Swigris JJ, Yorke J, Sprunger DB, Swearingen C, Pincus T, du Bois RM, et al. Assessing dyspnea and its impact on patients with connective tissue disease-related interstitial lung disease. Respir Med. (2010) 104:1350-5. doi: 10.1016/j.rmed.2010.03.027

114. Swigris JJ, Han M, Vij R, Noth I, Eisenstein EL, Anstrom KJ, et al. The UCSD shortness of breath questionnaire has longitudinal construct validity in idiopathic pulmonary fibrosis. Respir Med. (2012) 106:1447-55. doi: 10.1016/j.rmed.2012.06.018

115. King TE, Bradford WZ, Castro-Bernardini S, Fagan EA, Glaspole I, Glassberg $\mathrm{MK}$, et al. A phase 3 trial of pirfenidone in patients with idiopathic pulmonary fibrosis. $N$ Engl J Med. (2014) 370:2083-92. doi: 10.1056/NEJMoa1402582

116. Noble PW, Albera C, Bradford WZ, Costabel U, Glassberg MK, Kardatzke D, et al. Pirfenidone in patients with idiopathic pulmonary fibrosis (CAPACITY): two randomised trials. Lancet. (2011) 377:1760-9. doi: 10.1016/S0140-6736(11)60405-4

117. Nishiyama O, Taniguchi H, Kondoh Y, Kimura T, Kato K, Kataoka $\mathrm{K}$, et al. A simple assessment of dyspnoea as a prognostic indicator in idiopathic pulmonary fibrosis. Eur Respir J. (2010) 36:1067-72. doi: 10.1183/09031936.00152609

118. Rajala K, Lehto JT, Sutinen E, Kautiainen H, Myllärniemi M, Saarto T. mMRC dyspnoea scale indicates impaired quality of life and increased pain in patients with idiopathic pulmonary fibrosis. ERJ Open Res. (2017) 3:00084-2017. doi: 10.1183/23120541.00084-2017

119. King TE, Brown KK, Raghu G, du Bois RM, Lynch DA, Martinez F, et al. BUILD-3: a randomized, controlled trial of bosentan in idiopathic pulmonary fibrosis. Am J Respir Crit Care Med. (2011) 184:92-9. doi: 10.1164/rccm.201011-1874OC

120. Mahler DA, Witek TJ. The MCID of the transition dyspnea index is a total score of one unit. COPD. (2005) 2:99-103. doi: 10.1081/COPD-200050666

121. Khanna D, Tseng C-H, Furst DE, Clements PJ, Elashoff R, Roth M, et al. Minimally important differences in the Mahler's Transition Dyspnoea Index in a large randomized controlled trial-results from the Scleroderma Lung Study. Rheumatology. (2009) 48:1537-40. doi: 10.1093/rheumatology/kep284

122. Birring SS, Prudon B, Carr AJ, Singh SJ, Morgan MDL, Pavord ID. Development of a symptom specific health status measure for patients with chronic cough: LEICESTER Cough Questionnaire (LCQ). Thorax. (2003) 58:339-43. doi: 10.1136/thorax.58.4.339

123. Key AL, Holt K, Hamilton A, Smith JA, Earis JE. Objective cough frequency in Idiopathic Pulmonary Fibrosis. Cough. (2010) 6:4. doi: 10.1186/1745-9974-6-4

124. Scholand MB, Wolff R, Crossno PF, Sundar K, Winegar M, Whipple S, et al. Severity of cough in idiopathic pulmonary fibrosis is associated with MUC5 B genotype. Cough. (2014) 10:3. doi: 10.1186/1745-9974-10-3

125. Lechtzin N, Hilliard ME, Horton MR. Validation of the Cough Quality-ofLife Questionnaire in patients with idiopathic pulmonary fibrosis. Chest. (2013) 143:1745-9. doi: 10.1378/chest.12-2870

126. De Vries J, Michielsen H, Van Heck GL, Drent M. Measuring fatigue in sarcoidosis: the Fatigue Assessment Scale (FAS). Br J Health Psychol. (2004) 9(Pt 3):279-91. doi: 10.1348/1359107041557048

127. de Kleijn WPE, De Vries J, Wijnen PAHM, Drent M. Minimal (clinically) important differences for the Fatigue Assessment Scale in sarcoidosis. Respir Med. (2011) 105:1388-95. doi: 10.1016/j.rmed.2011.05.004

128. Drent M, Lower EE, De Vries J. Sarcoidosis-associated fatigue. Eur Respir J. (2012) 40:255-63. doi: 10.1183/09031936.00002512

129. Atkins CP, Gilbert D, Brockwell C, Robinson S, Wilson AM. Fatigue in sarcoidosis and idiopathic pulmonary fibrosis: differences in character and severity between diseases. Sarcoidosis Vasc Diffuse Lung Dis. (2016) 33:130-8.

130. Lee YJ, Choi SM, Lee YJ, Cho Y-J, Yoon HI, Lee J-H, et al. Clinical impact of depression and anxiety in patients with idiopathic pulmonary fibrosis. PLoS ONE. (2017) 12:e0184300. doi: 10.1371/journal.pone.0184300

131. Matsuda T, Taniguchi H, Ando M, Kondoh Y, Kimura T, Kataoka K, et al. Depression is significantly associated with the health status in patients with idiopathic pulmonary fibrosis. Intern Med. (2017) 56:1637-44. doi: 10.2169/internalmedicine.56.7019

132. Glaspole IN, Watson AL, Allan H, Chapman S, Cooper WA, Corte TJ, et al. Determinants and outcomes of prolonged anxiety and depression in idiopathic pulmonary fibrosis. Eur Respir J. (2017) 50:1700168. doi: 10.1183/13993003.00168-2017

133. Stern AF. The hospital anxiety and depression scale. Occup Med. (2014) 64:393-4. doi: 10.1093/occmed/kqu024

134. Johns MW. A new method for measuring daytime sleepiness: the Epworth sleepiness scale. Sleep. (1991) 14:540-5. doi: 10.1093/sleep/14.6.540

135. Lancaster LH, Mason WR, Parnell JA, Rice TW, Loyd JE, Milstone AP, et al. Obstructive sleep apnea is common in idiopathic pulmonary fibrosis. Chest. (2009) 136:772-8. doi: 10.1378/chest.08-2776

136. Mermigkis C, Stagaki E, Tryfon S, Schiza S, Amfilochiou A, Polychronopoulos V, et al. How common is sleep-disordered breathing in patients with idiopathic pulmonary fibrosis? Sleep Breath. (2010) 14:387-90. doi: 10.1007/s11325-010-0336-5

137. Ware JE, Sherbourne CD. The MOS 36-item short-form health survey (SF-36). I. Conceptual framework and item selection. Med Care. (1992) 30:473-83. doi: 10.1097/00005650-199206000-00002

138. Chang JA, Curtis JR, Patrick DL, Raghu G. Assessment of health-related quality of life in patients with interstitial lung disease. Chest. (1999) 116:1175-82. doi: 10.1378/chest.116.5.1175

139. Martinez TY, Pereira CA, dos Santos ML, Ciconelli RM, Guimarães SM, Martinez JA. Evaluation of the short-form 36-item questionnaire to measure health-related quality of life in patients with idiopathic pulmonary fibrosis. Chest. (2000) 117:1627-32. doi: 10.1378/chest.117.6.1627

140. Tomioka H, Imanaka $\mathrm{K}$, Hashimoto $\mathrm{K}$, Iwasaki $\mathrm{H}$. Health-related quality of life in patients with idiopathic pulmonary fibrosis-crosssectional and longitudinal study. Intern Med. (2007) 46:1533-42. doi: 10.2169/internalmedicine.46.6218

141. Khanna D, Clements PJ, Furst DE, Chon Y, Elashoff R, Roth MD, et al. Correlation of the degree of dyspnea with health-related quality of life, functional abilities, and diffusing capacity for carbon monoxide in patients with systemic sclerosis and active alveolitis: results from the Scleroderma Lung Study. Arthritis Rheum. (2005) 52:592-600. doi: 10.1002/art. 20787

142. Herdman M, Gudex C, Lloyd A, Janssen M, Kind P, Parkin D, et al. Development and preliminary testing of the new five-level version of EQ-5D (EQ-5D-5L). Qual Life Res. (2011) 20:1727-36. doi: 10.1007/s11136-011-9903-X

143. Mulhern B, Feng Y, Shah K, Janssen MF, Herdman M, van Hout B, et al. Correction to: comparing the UK EQ-5D-3L and English EQ-5D-5L value sets. Pharmacoeconomics. (2018) 36:727. doi: 10.1007/s40273-0180648-z

144. Szentes BL, Kreuter M, Bahmer T, Birring SS, Claussen M, Waelscher J, et al. Quality of life assessment in interstitial lung diseases:a comparison of the disease-specific K-BILD with the generic EQ-5D-5L. Respir Res. (2018) 19:101. doi: 10.1186/s12931-018-0808-x

145. Tsai APY, Hur SA, Wong A, Safavi M, Assayag D, Johannson KA, et al. Minimum important difference of the EQ-5D-5L and EQVAS in fibrotic interstitial lung disease. Thorax. (2021) 76:37-43. doi: 10.1136/thoraxjnl-2020-214944

146. Cella D, Yount S, Rothrock N, Gershon R, Cook K, Reeve B, et al. The patientreported outcomes measurement information system (PROMIS): Progress of an NIH roadmap cooperative group during its first two years. Med Care. (2007) 45(5 Suppl. 1):S3-11. doi: 10.1097/01.mlr.0000258615.42478.55

147. Yount SE, Beaumont JL, Chen S-Y, Kaiser K, Wortman K, Van Brunt DL, et al. Health-related quality of life in patients with idiopathic pulmonary fibrosis. Lung. (2016) 194:227-34. doi: 10.1007/s00408-016-9850-y

148. Fisher CJ, Namas R, Seelman D, Jaafar S, Homer K, Wilhalme H, et al. Reliability, construct validity and responsiveness to change of the PROMIS-29 in systemic sclerosis-associated interstitial lung disease. Clin Exp Rheumatol. (2019) 37(Suppl. 119):49-56.

149. Prior TS, Hilberg O, Shaker SB, Davidsen JR, Hoyer N, Birring SS, et al. Validation of the King's brief interstitial lung disease questionnaire in idiopathic pulmonary fibrosis. BMC Pulm Med. (2019) 19:255. doi: 10.1186/s12890-019-1018-0 
150. Silveira K, Steidle LJM, Matte DL, Tavares PH, Pincelli MP, Pizzichini MMM, et al. Translation and cultural adaptation of the King's Brief Interstitial Lung Disease health status questionnaire for use in Brazil. J Bras Pneumol. (2019) 45:e20180194. doi: 10.1590/1806-3713/e20180194

151. Pan R-L, Swigris JJ, Zhao Y-W, Guo A-M, Wu Q, Li S-J. Reliability and validity of Chinese version of a tool to assess the quality of life in idiopathic pulmonary fibrosis in patients with interstitial lung disease. Int J Nurs Sci. (2019) 6:38-42. doi: 10.1016/j.ijnss.2018.11.005

152. Yorke J, Moosavi SH, Shuldham C, Jones PW. Quantification of dyspnoea using descriptors: development and initial testing of the Dyspnoea-12. Thorax. (2010) 65:21-6. doi: 10.1136/thx.2009.118521

153. Yorke J, Swigris J, Russell A-M, Moosavi SH, Ng Man Kwong G, Longshaw $\mathrm{M}$, et al. Dyspnea-12 is a valid and reliable measure of breathlessness in patients with interstitial lung disease. Chest. (2011) 139:159-64. doi: 10.1378/chest.10-0693

154. Taniguchi $\mathrm{H}, \mathrm{Xu} \mathrm{Z}$, Azuma A, Inoue $\mathrm{Y}$, Li H, Fujimoto $\mathrm{T}$, et al.

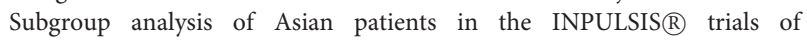
nintedanib in idiopathic pulmonary fibrosis. Respirology. (2016) 21:1425-30. doi: $10.1111 /$ resp. 12852

155. Xu Z, Li H, Wen F, Bai C, Chen P, Fan F, et al. Subgroup analysis for chinese patients included in the INPULSIS $($ trials on nintedanib in idiopathic pulmonary fibrosis. Adv Ther. (2019) 36:621-31. doi: 10.1007/s12325-019-0887-1

156. Azuma A, Chung L, Behera D, Chung M, Kondoh Y, Ogura T, et al. Efficacy and safety of nintedanib in Asian patients with systemic sclerosis-associated interstitial lung disease: subgroup analysis of the SENSCIS trial. Respir Investig. (2021) 59:252-9. doi: 10.1016/j.resinv.2020.10.005

157. Distler O, Highland KB, Gahlemann M, Azuma A, Fischer A, Mayes MD, et al. Nintedanib for systemic sclerosis-associated interstitial lung disease. $N$ Engl J Med. (2019) 380:2518-28. doi: 10.1056/NEJMoa1903076

158. van Manen MJG, Birring SS, Vancheri C, Vindigni V, Renzoni E, Russell A-M, et al. Effect of pirfenidone on cough in patients with idiopathic pulmonary fibrosis. Eur Respir J. (2017) 50:1701157. doi: 10.1183/13993003.011 57-2017

159. Suzuki A, Sakaguchi H, Sakamoto K, Ebina M, Azuma A, Ogura T, et al. The effect of pirfenidone on the prescription of antibiotics and antitussive drugs in patients with idiopathic pulmonary fibrosis: a post hoc exploratory analysis of phase III clinical trial. Chest. (2021). doi: 10.1016/j.chest.2021.05.058. [Epub ahead of print].

160. Kronborg-White S, Andersen CU, Kohberg C, Hilberg O, Bendstrup E. Palliation of chronic breathlessness with morphine in patients with fibrotic interstitial lung disease - a randomised placebo-controlled trial. Respir Res. (2020) 21:195. doi: 10.1186/s12931-020-01452-7

161. US Department of Health and Human. Guidance for Industry-PatientReported Outcome Measures: Use in Medical Product Development to Support Labeling Claims (2009). Available online at: http://www.fda.gov (accessed July 19, 2021).

162. Committee for Medicinal Products for Human Use. European Medicines Agency. Reflection Paper on the Regulatory Guidance for the Use of HealthRelated Quality of Life (HRQL) Measures in the Evaluation of Medicinal Products (2005). Available online at: https://www.ema.europa.eu/en/ documents/scientific-guideline/reflection-paper-regulatory-guidance-usehealthrelated-quality-life-hrql-measures-evaluation_en.pdf

163. Sauleda J, Núñez B, Sala E, Soriano JB. Idiopathic pulmonary fibrosis: epidemiology, natural history, phenotypes. Med Sci. (2018) 6:110. doi: $10.3390 /$ medsci6040110

Conflict of Interest: The authors declare that the research was conducted in the absence of any commercial or financial relationships that could be construed as a potential conflict of interest.

Publisher's Note: All claims expressed in this article are solely those of the authors and do not necessarily represent those of their affiliated organizations, or those of the publisher, the editors and the reviewers. Any product that may be evaluated in this article, or claim that may be made by its manufacturer, is not guaranteed or endorsed by the publisher.

Copyright $\odot 2021$ Aronson and Suzuki. This is an open-access article distributed under the terms of the Creative Commons Attribution License (CC BY). The use, distribution or reproduction in other forums is permitted, provided the original author(s) and the copyright owner(s) are credited and that the original publication in this journal is cited, in accordance with accepted academic practice. No use, distribution or reproduction is permitted which does not comply with these terms. 